\title{
FORMAÇÃO DE PROFESSORES PARA INTEGRAÇÃO DE TECNOLOGIAS DIGITAIS AO CURRÍCULO: UMA NARRATIVA E MUITAS AÇÕES
}

\author{
Ivanete Fátima BLAUTH ${ }^{\mathrm{i}}$ \\ Suely SCHERER ${ }^{\text {ii }}$
}

\begin{abstract}
RESUMO
Este artigo tem objetivo de apresentar uma narrativa sobre um processo de formação continuada de professoras para a integração de tecnologias digitais ao currículo dos anos iniciais do Ensino Fundamental, que ocorreu nos anos de 2017 e 2018, em uma escola pública de Campo Grande/MS, e contou com a participação de três pesquisadoras e cinco professoras. A partir de dados produzidos, foi estabelecido diálogo com estudos de Bittar e Sánchez, sobre processos de integração, e estudos de Mishra e Koehler, acerca de conhecimentos de professores, em especial, o conhecimento tecnológico pedagógico de conteúdo. Consideramos que o fato de estarem juntas, pesquisadoras e professoras, durante dois anos, na escola, produzindo planejamentos e práticas, oportunizou momentos de formação e aprendizagem, pois foi possível vivenciar no ambiente escolar um processo de integração de tecnologias digitais ao currículo dos anos iniciais.
\end{abstract}

PALAVRAS-CHAVE: Formação Continuada em Serviço; Escola; Conhecimento tecnológico pedagógico de conteúdo; Anos iniciais.

\section{TEACHER TRAINING TO INTEGRATE DIGITAL TECHNOLOGIES TO THE CURRICULUM: A NARRATIVE AND MANY ACTIONS}

\begin{abstract}
This paper has the objective to present a narrative about a process of continuing training for teachers working in integrate digital technologies into the curriculum of the early years of Ensino Fundamental (elementary school), occurred in 2017 and 2018, in a public school in Campo Grande/MS and had the participation of three researchers and five teachers. Based on the date produced, a dialogue was established with studies by Bittar and Sánchez about integration processes, and studies by Mishra and Koehler on teachers' knowledge, specially the pedagogical technological content knowledge. We consider that to be together, researchers and teachers, for two years, in this school, producing plans and practices, provided opportunities for training and learning, because it was possible to experience the school environment, a process of integrating digital technologies into the curriculum of the early years.
\end{abstract}

KEYWORDS: Continuing Training in Service; School; Technological pedagogical content knowledge; Initial years.

\footnotetext{
${ }^{i}$ Doutoranda no Programa de Pós-Graduação em Educação Matemática na Universidade Federal de Mato Grosso do Sul. E-mail: ivanetefatima@ hotmail.com.

ii Pós-doutorado em Educação pela UFPR, Doutorado em Educação pela PUC-SP. Professora associada na Universidade Federal de Mato Grosso do Sul. E-mail: suely.scherer@ufms.br.
} 


\title{
FORMACIÓN DE PROFESORES PARA LA INTEGRACIÓN DE TECNOLOGÍAS DIGITALES AL CURRÍCULO: UNA NARRATIVA Y MUCHAS ACCIONES
}

\begin{abstract}
RESUMEN
Este artículo tiene por objetivo presentar una narrativa sobre un proceso de formación continua de profesores al integrar tecnologías digitales en el currículo de los primeros años de Enseñanza Fundamental, que ocurrió en los años 2017 y 2018, en una escuela pública en Campo Grande/MS y contó con la participación activa de tres investigadores y cinco docentes. A partir de datos producidos, se estableció un diálogo con estudios de Bittar y Sánchez sobre procesos de integración, y los estudios de Mishra y Koehler sobre el conocimiento de los docentes, en especial, el conocimiento tecnológico pedagógico del contenido. Creemos que estar juntos, investigadores y maestros, durante dos años, en la escuela, produciendo planeamientos y prácticas, brindó oportunidades de formación y aprendizaje, ya que fue posible experimentar en el entorno escolar, un proceso de integración de tecnologías digitales al currículo en los estudios de los primeros años.
\end{abstract}

PALABRAS CLAVE: Capacitación continua en servicio; Escuela; Conocimiento tecnológico pedagógico del contenido; Años iniciales.

\section{UMA BREVE INTRODUÇÃO...}

Freire (1996, p. 16) afirmou que "só somos porque estamos sendo. Estar sendo é a condição, entre nós, para ser”. Essa frase nos faz pensar no processo contínuo de vir a ser, na incompletude do ser humano e em sua capacidade de intervir, fazer escolhas, apreender o novo; na possibilidade de construir e reconstruir conhecimentos para viver em sociedade. E é nessa condição de incompletude, de sempre "estar sendo", que discutimos a integração da tecnologia digital ao currículo escolar, pois a maioria de nós está em contínuo processo de integração à cultura digital, ao consumir e produzir significados, diariamente, na interação com tecnologias digitais (smartphones, tablets, computadores).

E as escolas? E os currículos escolares? Que movimentos de integração à cultura digital professores, alunos, gestores, comunidades escolares... têm vivenciado? São currículos prontos e acabados, ou orientados pela incompletude do ser humano e da complexidade de suas relações? São essas e outras questões que nos mobilizaram a propor e desenvolver a pesquisa que discutimos neste artigo, considerando a condição de vir a ser, de estar sendo, de pesquisadoras e professoras/formadoras; da escola que escolhemos como parceira; dos professores que convidamos para estudar conosco em um processo de formação continuada; da escola; dos gestores; das crianças que estudam nos anos iniciais nessa escola parceira; dos currículos prescritos...

Em um contexto urbano, em que observamos que tecnologias digitais estão em contínuo 
processo de integração à vida em comunidade, independentemente de geração, não é fácil imaginar que esse movimento de integração pouco está presente nas escolas localizadas nessas comunidades. As crianças/adolescentes/jovens que frequentam a escola nas áreas urbanas, em especial, se constituem e constituem, a cada dia, na/a cultura digital. As escolas que se constituem, a cada dia nessas comunidades, como organismos vivos que são (gestores, professores, alunos, pais e responsáveis, comunidade...) precisam refletir, continuadamente, sobre os currículos propostos e em ação, sugerir novos currículos, integrados a uma cultura também digital. Acreditamos que processos de formação continuada de professores, em serviço, podem mobilizar a escola nesse sentido, partindo de suas potencialidades e fragilidades, em diálogo e parceria... E assim surgiu a proposta desta pesquisa.

A pesquisa, financiada pela Fundação de Apoio ao Ensino, Ciência e Tecnologia do Estado do Mato Grosso do Sul (FUNDECT), na chamada FUNDECT/CAPES n. ${ }^{\circ}$ 11/2015 Educa MS - Ciência e Educação Básica, com o apoio da Universidade Federal de Mato Grosso do Sul (UFMS), foi intitulada "Integração de Tecnologias Digitais ao Currículo dos Anos Iniciais do Ensino Fundamental: Desafios para/na Inovação”, cujo objetivo foi investigar um processo de formação de professoras que atuavam com alunos dos anos iniciais do Ensino Fundamental, em uma escola pública de Campo Grande/MS.

O processo de formação continuada em serviço teve por propósito oportunizar a vivência de um processo de integração de tecnologias digitais ao currículo escolar. Realizado durante os anos de 2017 e 2018, diretamente no espaço da escola, contou com a participação de cinco professoras da escola e três pesquisadoras da universidade (duas autoras deste artigo). No entanto, a pesquisa e as ações de formação envolveram outras pesquisadoras, direção e coordenadoras pedagógicas, em diferentes momentos. As ações dessa formação foram constituídas por reuniões quinzenais para planejamento e avaliação de aulas; observação e acompanhamento de aulas; reuniões coletivas mensais e oficinas sobre temas de interesse das professoras.

Neste artigo, o objetivo é apresentar uma narrativa sobre esse processo de formação. Os dados produzidos para essa narrativa são anotações das pesquisadoras, diários de campo e gravações de áudio dos encontros de formação entre pesquisadoras e professoras, ao longo desses dois anos que estivemos com as professoras na escola. Dos áudios selecionamos trechos de relatos das professoras que davam indícios de movimentos de mobilização e construção de 
conhecimentos para integração de tecnologias digitais ao currículo. A escolha dos relatos foi realizada a partir de uma audição das gravações e buscas em anotações nos diários de campo das pesquisadoras.

Na narrativa, apresentamos alguns movimentos do processo de formação continuada das professoras, uma narrativa produzida a partir do ponto de vista de duas pesquisadoras (autoras deste artigo), constituída por diferentes movimentos e ações na escola. Contudo, antes vamos anunciar o que compreendemos por narrativas...

Almir Eduardo Melke Sater, cantor sul-mato-grossense, e Renato Teixeira de Oliveira, na composição da música "Tocando em frente", mencionaram que "Cada um de nós compõe a sua história... Cada ser em si... Carrega o dom de ser capaz... E ser feliz”. Portanto, parafraseando referidos compositores, consideramos que cada um de nós compõe narrativas, expressando um modo particular de pensar, a partir de sua história, de seus conhecimentos e maneiras de ver e ser no mundo, com o mundo; afinal, somos participantes e constituintes de culturas, podemos atuar como produtores e consumidores delas, integrando ao nosso cotidiano significados, jeitos de ser e fazer produzidos com/nessa/para essa cultura.

Rodrigues, Almeida e Valente (2017, p. 64) afirmaram que "as narrativas são uma forma de contar, uma maneira de lembrar, um jeito de registrar as memórias, reviver as histórias e (re) significar o vivido". É essa relação que buscamos estabelecer ao escrever este artigo, um modo de narrar o que lembramos/vivenciamos durante um período, ao participar/interagir com professoras dos anos iniciais do Ensino Fundamental, durante dois anos de um processo de formação continuada com/para integração de tecnologias digitais ao currículo. Ao narrar esse processo, trazemos relatos/reflexões feitas pelas professoras e por nós, durante esse período, possibilitando algumas análises sobre esse processo vivenciado/compartilhado.

\section{UM CAMINHAR... EM UM PROCESSO DE FORMAÇÃO... MUITOS DADOS PRODUZIDOS...}

Então, vamos lá? Persistir, insistir, "compreender a marcha e ir tocando em frente" (SATER; OLIVEIRA, 1990), foi o que nos movimentou durante os três anos ou mais, desde o início desta pesquisa; nos dois anos diretamente na escola; no caminho construído em um processo de formação continuada de professores, em uma escola pública de Campo Grande/MS.

O processo de pesquisa iniciou em 2015, ao escrevermos um projeto, submetê-lo e 
aguardarmos a aprovação pela agência de financiamento, o que se efetivou apenas no segundo semestre de 2016, para, então, em 2017, iniciarmos as atividades na escola, interagindo com um grupo de professoras (um novo convite a todas as professoras dos anos iniciais e gestores, pois somente duas já estavam no projeto desde o início, em 2015), com o ambiente escolar, com os alunos, ou seja, começamos a pesquisar/viver/estar, vivenciando momentos nessa escola, não como professoras contratadas para nela trabalhar, mas como professoras/pesquisadoras/colegas de profissão, que estavam dispostas a vivenciar/estar com as professoras participantes da pesquisa, desse processo de formação/aprendizagem... em um movimento de estar sendo... de devir...

Um caminhar, a construção de um percurso, um movimento que se iniciava, cientes do grande desafio que é vivenciar a formação continuada de professores para integrar tecnologias ao currículo em uma escola. Trata-se de um desafio que, de acordo com Almeida e Valente (2011), requer muito mais que dialogar com/sobre conhecimentos técnicos e pedagógicos; envolve dialogar com uma base de conhecimentos e crenças dos professores, considerar cenários (infraestrutura das escolas, gestão, comunidade escolar...) e contextos de aprendizagem (aspectos emocionais, cognitivos, afetivos, fisiológicos...) para interagir com os professores e "construir conhecimentos sobre os aspectos computacionais; compreender as perspectivas educacionais subjacentes aos softwares em uso; entender por que e como integrar o computador com o currículo e como concretizar esse processo na sua prática pedagógica" (ALMEIDA; VALENTE, 2011, p. 50).

Assim, cientes desse desafio, iniciamos um processo de formação continuada com um grupo de oito professoras/pesquisadoras (três pesquisadoras da Universidade e cinco professoras da escola) que se dedicaram cotidianamente à pesquisa, além de outros pesquisadores e colaboradores da escola com contribuições mais pontuais. Esse processo, movimento de formação, foi um caminho construído, um processo vivenciado por esse grupo, um processo "realimentado, reorientado e bifurcado sempre que necessário pela ação dos envolvidos no cenário educacional" (MORAES, 2010, p. 4). Um caminho que se (re)inventava a cada nova situação, de acordo com as necessidades, desafios e imprevistos... em movimento... em processo de (re)pensar constante...

Dizemos processo de formação porque as ações de formação não foram pontuais, isoladas, mas contínuas, de interação entre pesquisadoras e professoras, seja na escola (durante 
os planejamentos, o desenvolvimento de aulas, as observações de aulas, as conversas de corredor), conversas pelo WhatsApp, ou então na Universidade, quando das reuniões coletivas de estudo e avaliação. Sempre um processo de formação-reflexão-ação (adiante abordaremos esse aspecto), diferente para cada professora e situação, a partir, mas não só, do currículo prescrito nas orientações da rede municipal de ensino, para cada turma de alunos.

Para essa pesquisa foram convidadas professoras efetivas, concursadas (pois contratos temporários impediriam as professoras de participarem de todo o processo naquela escola, nossa intenção inicial, para discutir integração de tecnologias ao currículo), que atuavam nessa escola como regentes de turmas de alunos dos anos iniciais do Ensino Fundamental. Na escola havia várias professoras, porém nem todas, mesmo concursadas se dispuseram a participar da proposta, resultando em cinco professoras participantes da pesquisa, durante o ano de 2017. Entretanto, com a desistência de uma delas por motivos particulares, em 2018, nossos encontros foram realizados com quatro professoras.

A seguir, no Quadro 1, apresentaremos um resumo das ações de formação propostas/desenvolvidas no grupo com a participação das professoras. Ressaltamos que por questões éticas não publicaremos o nome real das participantes, que assim serão chamadas: Ana, Bia, Léa, Isa e Bet.

Quadro 1 - Ações propostas e participação das professoras

\begin{tabular}{|c|c|c|c|c|c|}
\hline Ações/Total de participações & Ana & Bia & Léa & Isa & Bet \\
\hline Entrevista e formulário & 07.02 .2017 & 08.02 .2017 & 08.02 .2017 & 07.02 .2017 & 07.02 .2017 \\
\hline Planejamentos $1 .^{\circ}$ semestre 2017 & 8 & 8 & 5 & 5 & 6 \\
\hline Reunião coletiva $1 .^{\circ}$ semestre & 2 & 2 & 1 & 1 & 1 \\
\hline Oficinas 2017 & 2 & 2 & 1 & 1 & 2 \\
\hline Planejamentos 2. ${ }^{\circ}$ semestre 2017 & 7 & 7 & 7 & 6 & 4 \\
\hline Reunião coletiva $2 .^{\circ}$ semestre & 3 & 3 & 1 & 1 & 3 \\
\hline Observação de aulas $2 .^{\circ}$ semestre & 15 & 29 & 1 & 2 & 1 \\
\hline Entrevista final de 2017 & 28.11 .2017 & 11.11 .2017 & 11.12 .2017 & 07.12 .2017 & 04.12 .2017 \\
\hline Planejamentos $1 .^{\circ}$ semestre 2018 & 7 & 8 & 5 & 6 & 1 \\
\hline Observação de aulas 2018 & 13 & 16 & 1 & 1 & - \\
\hline Reuniões coletivas/oficinas em 2018 & 5 & 5 & 3 & 4 & - \\
\hline
\end{tabular}

Fonte: Dados da pesquisa (as autoras, 2020).

Como apresentado no Quadro 1, as ações propostas para essa formação foram mudando com o passar do tempo, de acordo com as possibilidades e necessidades que surgiam. No ano de 2017 e no $1 .^{\circ}$ semestre de 2018, as ações se voltaram mais para encontros de planejamento quinzenal, individual, com cada professora. No 2. ${ }^{\circ}$ semestre de 2017 e $1 .^{\circ}$ semestre de 2018 , 
optamos por, além de planejar e avaliar aulas com as professoras, observar e acompanhar aulas de Matemática, em especial, pois, conforme comentado pelas professoras nas reuniões de planejamento, há dificuldade de alguns alunos em aprender conceitos dessa área e delas em integrar as tecnologias ao currículo de Matemática. Ademais, havia o interesse de duas pesquisadoras no ensino de Matemática em virtude de sua área de formação.

As observações/acompanhamento de aulas foram realizadas, em maior número, nas aulas de duas professoras, Ana e Bia, que se mostraram interessadas e permitiram nossa convivência com os alunos delas. O acompanhamento das aulas de Matemática ministradas pela professora Bia, e de seu processo de formação nesse período, resultou em uma pesquisa de mestrado (CORRÊA, 2019).

Além dessas ações, durante o ano de 2017 foram realizadas algumas reuniões coletivas de avaliação e planejamento e duas oficinas (sobre lousa digital e Wiki). Em 2018, optamos por mudar o formato desses encontros: não foram realizados no primeiro semestre (por questões de tempo e incompatibilidade de horários das professoras) e, no segundo semestre, passaram a ser mensais, com dois momentos: um para discutir ideias de planejamento e realizar avaliações e reflexões sobre o que as professoras vinham realizando nas aulas; e outro para estudar textos e desenvolver oficinas sobre temas de interesse das professoras (produção de vídeos, uso de jogos, produção de histórias em quadrinhos).

No segundo semestre de 2018, não foram realizadas reuniões quinzenais de planejamento com as professoras na escola; por esse motivo, o primeiro momento, nas reuniões coletivas, foi destinado ao diálogo sobre as aulas. Nossa intenção era de avaliar a autonomia das professoras em planejar e desenvolver aulas em um processo de integrar tecnologias digitais ao currículo, após um ano e meio de parceria nos planejamentos.

As ações dessa formação foram gravadas em áudio e alguns vídeos e se constituíram nos dados produzidos para a pesquisa, com os diários de campo das pesquisadoras de reuniões e observações de aulas. A partir desses dados e das ações desenvolvidas na escola, foram realizadas algumas escolhas para comporem a narrativa que apresentamos neste artigo; são dados que nos auxiliaram a relatar alguns trechos dessa "longa estrada", desse percurso/período em que vivenciamos, com esse grupo de professoras, a formação na escola. Além disso, com esses dados foi possível identificar e analisar alguns aspectos da formação que podem ter contribuído com a construção de conhecimento tecnológico pedagógico de conteúdo (CTPC) 
das professoras participantes.

Importante mencionar que, a partir de dados produzidos nessa pesquisa, também está em construção, em fase de finalização, uma pesquisa de doutorado, mas esta se constituirá em outra narrativa...

\section{UMA NARRATIVA... UM PROCESSO DE FORMAÇÃO CONTINUADA... UM GRUPO DE PROFESSORAS E PESQUISADORAS... UMA ESCOLA...}

O processo de formação continuada que discutimos neste artigo não se configurou como um curso, uma palestra, um seminário ou um minicurso/oficina. Foi tudo isso e nada disso ao mesmo tempo, pois as relações/inter-relações vivenciadas nesse processo foram complexas, múltiplas, contínuas, não constituídas em uma relação de "isso ou aquilo", mas de "isso e aquilo e daquele outro...”. Um processo de estar junto com as professoras, no espaço da escola, construindo planejamentos, ideias, refletindo, analisando, avaliando, desenvolvendo aulas, produzindo um novo currículo ao integrar as tecnologias digitais que podiam ser disponibilizadas na escola.

Podemos dizer que se configurou como um processo de formação continuada em serviço. Segundo Valente (1999), esse tipo de formação é realizado na escola, o que possibilita resultados mais imediatos com relação ao uso de tecnologias digitais nas atividades de sala de aula das professoras, uma vez que as professoras podem aprender no contexto em que atuam, contando com o auxílio de especialistas (nessa pesquisa, nós, as pesquisadoras). Ademais, foi possível dialogar/conversar/vivenciar com "suas dificuldades e problemas do dia a dia e durante um tempo suficiente para o amadurecimento das discussões acerca das situações vivenciadas" (BITTAR, 2011, p. 163).

A seguir, apresentaremos alguns movimentos, trazendo relatos de professoras dessa ação de formação, que evidenciam aspectos que consideramos importantes ao propor e vivenciar ações de formação continuada de professores para integração de tecnologias digitais ao currículo... Iniciaremos com dois relatos, um de Bia e um de Isa, em momentos distintos da formação, evidenciando aspectos que consideraram relevantes no movimento de formação por nós proposto.

Uma coisa que eu comento quase sempre [...]: que a Secretaria de Educação oferece formações, mas que na maioria das vezes são descontextualizadas do 
que vivemos, da realidade... [indicando que a formação em foco partia do contexto da escola]. É uma formação fora do contexto que vivemos. O que estamos tendo com o projeto, é a possibilidade de pensar e repensar a nossa forma de trabalhar em sala de aula, de forma prática, com pessoas que têm toda a competência, de poder estar junto com a gente, e trabalhar lado a lado para a aprendizagem das crianças [...]. O que mais me agrada de estar no projeto é essa possibilidade de trocar, e também de estar avaliando o jeito que você está dando aula. [...] É um apoio mesmo, para que possamos repensar se continuamos do jeito que estávamos fazendo, e o que podemos mudar, é muito marcante (Profa. Bia 1. .08.2017).

Eu acho que as formações da Secretaria de Educação precisariam mudar um pouco, porque lá eles trazem coisas lindas, muito direcionadas, sem muita oportunidade de diálogo, por exemplo, vamos falar de matemática, mas são coisas que não cabem na realidade do que acontece no dia a dia. Aqui (nesse processo de formação,) nós conseguimos fazer isso, cada uma fala das suas dificuldades, fala das suas práticas, e vamos dialogando, posso me sentir mais aliviada por pensar que não é só comigo que acontecem essas coisas (Profa. Isa 12.12.2018).

As professoras comentaram sobre aspectos importantes na vivência dessa formação proposta: dialogar e propor ações no contexto e realidade em que trabalham; o fato de formadoras e professoras, juntas, pensarem e repensarem aulas, avaliando aulas e práticas, currículos, o processo de integração de tecnologias; a relevância do diálogo na formação para planejar, avaliar aulas, refletir sobre todo o processo; e diríamos que essas falas também indicam a importância de ouvir as professoras em todo o processo de formação...

Esse processo de formação é um "modelo" que consideramos ser de formação-açãoreflexão, em que, a partir de encontros entre pesquisadoras e professoras (formação), são desenvolvidas aulas, realizadas ações/práticas em sala de aula, que orientam reflexões sobre esse processo no encontro seguinte, ao se realizar um novo planejamento/formação... E, assim, em um ciclo contínuo e articulado de formação. Afinal, a ação e a reflexão também fazem parte da formação.

As reuniões de planejamento, uma das ações de formação, eram quinzenais e ocorriam quase sempre em meio à rotina escolar, no contexto em que as professoras atuavam, nos horários que as professoras destinavam ao planejamento na escola (cada professora tinha direito a 33\% da carga horária semanal para planejamento de aulas na escola). Nesses encontros, cada professora trazia algumas ideias sobre como explorar o conteúdo previsto nas orientações curriculares da rede municipal de ensino, para a turma em que atuavam, para a quinzena seguinte. A partir dessas propostas, pensávamos juntas em atividades e ações que pudessem 
favorecer os processos de ensino e de aprendizagem de cada turma, considerando suas particularidades, que eram conhecidas aos poucos.

As ações de formação durante as reuniões de planejamento foram contínuas durante um ano e meio; um movimento de estarem juntas pesquisadoras e professora, que nesses encontros individuais de planejamento e avaliação envolviam-se sugestões para uso de aplicativos, leituras, avaliações (antes, durante e após as aulas), de forma articulada com o currículo prescrito e o perfil de cada grupo de alunos e professora, considerando as tecnologias disponíveis para utilização na escola. As ideias e propostas discutidas nos encontros não ficavam restritas ao conteúdo, porque compreendiam questões pedagógicas, assuntos relacionados à gestão e estrutura da escola, dúvidas da professora sobre conteúdos, metodologia, avaliação. Além disso, havia momentos de reflexão sobre as aulas desenvolvidas... dialogávamos sobre como foi, como poderia ter sido, ou o que observar para as aulas seguintes, ou seja, diálogos e reflexões sobre processos de ensino e de aprendizagem, assim como a prática/ação em sala de aula faziam parte desse processo de formação/aprendizagem com/para o uso de tecnologias digitais em aulas.

Ressaltamos que nenhum planejamento discutido nos encontros era considerado finalizado, acabado; sempre podia ser mudado, negociado, coconstruído na ação da professora com os alunos; ou, ainda, a partir de outros movimentos na escola, sala de aula, por vezes, antes de desenvolver as aulas planejadas no grupo, a professora fazia alterações. Outrossim, nenhum recurso pedagógico, seja digital ou analógico, sobressaía ao outro; eles eram integrados às aulas, ao currículo, a depender do objetivo de aprendizagem em cada aula. Sempre discutíamos que o objetivo era integrar as tecnologias digitais ao currículo, não realizar trocas, ou seja, não retirar outras tecnologias e deixar apenas as digitais.

Sabemos que nem tudo o que é planejado acontece na sala de aula, que sempre pode haver desordens, rupturas, imprevistos, e por essa razão as professoras vivenciavam um repensar constante das práticas pedagógicas. Em todos os momentos de planejamento, lembrávamos de que não há um fazer certo ou errado, e sim um movimento, conhecimentos em construção! Uma atividade discutida com duas professoras de uma mesma turma não se desenvolvia da mesma maneira em sala de aula, pois se considerava que os alunos eram outros, a professora era outra, que havia outros conhecimentos em jogo, diferentes interações... E, assim, a escola movimentava-se, modificava-se, de maneira singular, só dela, constituída e produzida por tantas pessoas e diferenças. 
Sempre que possível, pensávamos em alguma tecnologia digital que pudesse ser integrada às aulas para que os movimentos da aula, ao ser desenvolvida, pudessem se diferenciar do lápis e papel, se articular e integrar com outros materiais, tecnologias e linguagens. A intenção era integrar e não trocar, como mencionamos supra, talvez reorganizar e integrar recursos/materiais/tecnologias disponíveis na escola. No entanto, a decisão sobre o uso ou não de tal tecnologia sempre ficava sob responsabilidade de cada professora, pois era ela quem estava na sala de aula, que conhecia de fato as situações que ocorriam em sala, com os alunos, seus objetivos e suas necessidades. Portanto, era a professora que tinha autonomia em (re) organizar seu planejamento a partir das ideias discutidas nos encontros, construindo e reconstruindo o currículo na ação. Acerca dessa ação de planejar aulas e da parceria, o estar juntas professora e pesquisadoras, quinzenalmente, para planejar e avaliar aulas, currículo, resgatamos parte de um relato da professora Bia:

A grande diferença do projeto é que nós temos esse suporte, temos essa possibilidade de discutir o nosso plano de aula com vocês, e a partir disso pensar em possibilidades de inovações tecnológicas para dentro da sala de aula. As estratégias didáticas que vocês propõem para trabalharmos determinados conteúdos vinculados ao uso de tecnologia, isso com certeza é um ponto forte desse projeto. [...] a questão das orientações dos planos de aula [...] ca cada 15 dias tínhamos orientação do plano de aula. Junto com a orientação, além da questão da tecnologia, era orientado com relação as estratégias didáticas. Não falávamos especificamente sobre tecnologias, as vezes falávamos com relação ao conteúdo, as estratégias que poderiam ser adotadas para trabalhar aquele conteúdo, de uma forma que pudesse auxiliar esse processo de aprendizagem da criança, com a criança. Isso para mim, pelo menos, foi uma das coisas principais do projeto, essa questão de ter esse apoio, de ter alguém lendo, avaliando e colaborando, sugerindo dentro do plano de aula, a nossa atuação em sala de aula (Profa. Bia, 12.12.2017).

Esse relato nos faz pensar no processo de estar sendo da professora, do processo de (re)construção de conhecimento no tocante à integração de tecnologias, ao planejar aulas; na importância de que os professores tenham conhecimentos e possam discutir/dialogar sobre o uso de tecnologias digitais para explorar determinado conteúdo, articulado à metodologia, ao currículo em ação, porquanto conhecer as tecnologias e suas potencialidades é diferente de conhecer as tecnologias e pensar em possibilidades metodológicas para integrá-las a suas aulas, explorando determinado conteúdo com seus alunos.

Quanto à seleção de tecnologias digitais para integrar às aulas, era um trabalho árduo, tanto nosso (das pesquisadoras) como das professoras, uma vez que o desafio era escolher 
materiais digitais (jogos, applet, simulador, vídeo) que atendessem a algumas premissas de abordagem construcionista, ou seja, que professores e alunos pudessem explorar/construir conteúdos previstos nas orientações curriculares a partir da linguagem digital; que essas tecnologias favorecessem os objetivos da aula, com a turma, em diferentes áreas do conhecimento (Português, Matemática, Ciências, História e Geografia); que pudessem contribuir para a aprendizagem dos alunos; que os desafiassem a conjecturar e a produzir conhecimento; que ajudassem alunos a compartilhar ideias, descobertas, questões, comentários; que oportunizassem a construção de conhecimento a partir daquele material/tecnologia, das interações com a professora e colegas, das atividades propostas e da mediação pedagógica feita pela professora; além disso, sempre pensamos em situações que oportunizassem que os alunos interagissem, para aprender, para criar estratégias de resolução; eles (professores e alunos) produzindo conhecimento, colocando a mão na massa (PAPERT, 2008).

Acerca da observação e acompanhamento de aulas dessas professoras, inicialmente optamos por participar/observar apenas aulas de Matemática, em virtude do interesse de duas pesquisadoras do grupo, como mencionado anteriormente. No entanto, com o passar do tempo, observamos e acompanhamos outras aulas em sala, sempre que possível e quando éramos convidadas pelas professoras. Não se tratava apenas de observações, porque a interação com alunos e professora na sala era frequente e continuada... Com o decorrer do tempo, quando já habitávamos aquele espaço, a familiaridade com os alunos fez com que nossa observação fosse cada vez mais ativa, e, além do objetivo de analisar as aulas da professora, com a professora, dialogávamos com os alunos, pois eles tinham liberdade de interagir conosco e pedir ajuda, em muitos momentos.

Nos momentos de observação e acompanhamento, por vezes presenciamos um currículo prescrito sendo alterado na ação: "quando os professores alteram o planejado no andamento da prática pedagógica conforme as demandas emergentes de seus alunos, o seu fazer e refletir na ação" (ALMEIDA; VALENTE, 2011, p. 15), constituindo novos currículos na ação.

Além das reuniões de planejamento, fazíamos reuniões coletivas de planejamento, estudo e avaliação, que geralmente ocorriam na Universidade pela falta de um espaço na escola (aconteciam em período de aula, no horário comum de planejamento das professoras), e também para que os encontros se realizassem em nosso local de trabalho, para que elas pudessem conhecê-lo. A escola se localizava em um bairro próximo à Universidade, aproximadamente a 3 a $4 \mathrm{~km}$ de distância, o que facilitava o deslocamento, tanto nosso para a 
escola como das professoras para a Universidade.

Nessas reuniões, os diálogos giravam em torno da possibilidade de integração de tecnologias digitais ao currículo; as professoras falavam sobre suas aulas, as potencialidades de uso das tecnologias e também as dificuldades que encontravam em sala de aula e na escola. Pudemos constatar que geralmente as preocupações maiores das professoras eram a aprendizagem dos alunos; a infraestrutura da escola, que nem sempre permitia que as aulas planejadas pudessem ser desenvolvidas; e o currículo prescrito, pois algumas se angustiavam em não conseguir explorar todos os conteúdos previstos nas orientações curriculares propostas pela rede municipal de ensino.

Nessas reuniões coletivas também foram realizadas oficinas, a partir de interesses das professoras. Eram oficinas práticas e basicamente consistiam em fazer com que as professoras pudessem ter contato, interagir com as tecnologias (lousa digital, projetor multimídia e aplicativos como o Base Blocks, Wiki, editor de vídeos, HQs e jogos on-line), aprender como usar e pensar em possibilidades pedagógicas de uso de tais tecnologias.

Portanto, podemos afirmar que esse processo de formação foi um processo de aprendizagem contínua; um movimento de se tornar professora a cada dia; uma dinâmica de estar sendo... tanto para nós, pesquisadoras, quanto para as professoras. Poder vivenciar alguns dos movimentos complexos (que constituem planejamentos, desenvolvimento de aulas, avaliações, contextos e cultura dos alunos, gestão escolar, relações com pais e responsáveis, entre outros) produzidos e que produzem o espaço escolar, durante esses dois anos, oportunizou-nos diferentes experiências, momentos singulares a cada dia, com novas sensações a cada encontro, reunião, planejamento, observação de aula, avaliação das aulas desenvolvidas. Para as professoras, muitas vezes foi momento de desabafo, de preocupação com os alunos, de se sentirem ouvidas, de aprendizagem, de contato com algumas tecnologias desconhecidas, ou possibilidade de pensar outros modos de explorar algum conteúdo, de diálogo com as colegas e pesquisadoras, de confraternização em alguns momentos... Enfim, um movimento de estar sendo, tornar-se professoras e pesquisadoras a cada dia... o tempo todo agindo, pensando, problematizando...

Assim como essa formação, a cada novo momento, todos os dias, vamos nos constituindo, em um constante devir... tecemos novas redes, e estas se modificam com o movimento, articulando as partes para formar todos, que se constituem a cada momento... $\mathrm{E}$ 
nesse movimento sempre articulamos novos conhecimentos àqueles já construídos. Somos seres inacabados e, por conseguinte, nessa espiral ascendente de aprendizagem, temos oportunidade de interagir, relembrar, repensar, refazer ...; temos a certeza, como afirmam Sater e Oliveira (1990): "De que muito pouco sei... Ou nada sei”.

\section{UMA NARRATIVA... UM PROCESSO DE INTEGRAÇÃO DE TECNOLOGIAS DIGITAIS AO CURRÍCULO... ALGUNS RELATOS...}

E vamos "tocando em frente" ... Na seção anterior, contamos/narramos sobre algumas ações de um processo de formação/aprendizagem que vivenciamos ao interagir com professoras que atuam nos anos iniciais do Ensino Fundamental, em uma escola pública. Nesta seção, contaremos/narraremos algumas práticas desenvolvidas pelas professoras, a partir de relatos feitos por elas, nos nossos encontros de planejamento e avaliação de aulas. Relataremos alguns casos que selecionamos, em que identificamos possibilidade de movimentos em favor da construção de conhecimentos para integração de tecnologias digitais ao currículo. Dizemos movimentos pois consideramos que construir conhecimentos para integrar tecnologias ao currículo é um processo, que se modifica com o passar do tempo, de acordo com as tecnologias disponíveis, as pessoas, os conhecimentos. Logo, muitas vezes nos perguntamos: será que nesse movimento (que envolve diferentes ações da professora e alunos), as tecnologias estão mesmo sendo integradas? Ou estão apenas sendo usadas/inseridas nos ambientes escolares?

Para entender um pouco por que consideramos diferente a ação de inserir e de integrar tecnologias digitais ao currículo, trazemos alguns autores para dialogar conosco. Vamos lá... o que significa inserir? Bittar (2011, p. 159) afirmou que inserir "significa fazer uso desse instrumento sem que ele provoque aprendizagem, usando-o em situações desconectadas do trabalho em sala de aula". Essa tecnologia, que a autora chama de instrumento, quando inserida, não necessariamente está vinculada a um processo de aprendizagem dos alunos. É utilizada apenas como uma atividade à parte. Por exemplo, usar um jogo na sala de tecnologias, que não está articulado ao conteúdo explorado na disciplina, ou sem foco em alguma aprendizagem dos alunos; o professor propõe apenas o jogo pelo jogo, para brincar e usar o tempo de aula. Assim, não se discutem o conhecimento presente naquele jogo, possíveis relações com outros conhecimentos; possíveis dificuldades dos alunos ao jogar; outros registros.

Não é pelo fato de hoje as tecnologias estarem em toda parte que podemos dizer que a 
integração dessas tecnologias ao currículo acontece nas escolas. É necessário que inicialmente elas estejam nas escolas, e, caso sim, que sejam usadas, e, usadas, que sejam integradas ao currículo. Sánchez (2003, p. 52) considerou que “integrar as tecnologias digitais é torná-las parte do currículo, vinculando-as harmoniosamente com os demais componentes do currículo. É usá-las como parte integrante do currículo e não como um apêndice, não como um recurso periférico".

Ainda sobre integração, Lobo da Costa (2010, p. 94-95) afirmou que "integrar não é justapor, mas articular, estabelecer conexões e fazer uso pedagógico proveitoso - no sentido de construir conhecimento - para si e para o aluno". Logo, integrar pode se entender como a constituição de um novo inteiro, um novo currículo, em que não cabe mais mencionar separadamente tecnologias digitais e aulas (SCHERER, 2015). É integrar linguagens, tecnologias, com o objetivo de favorecer a aprendizagem do aluno. Nesse sentido, para Bittar (2011, p. 159), as tecnologias estão integradas à prática pedagógica quando "passa[m] a fazer parte do arsenal de que o professor dispõe para atingir seus objetivos. Implica em fazer uso do instrumento de forma que este contribua com o processo de aprendizagem do aluno, que lhe permita compreender, ter acesso, explorar diferentes aspectos do saber em cena".

Cabe salientar que, ao referirmos a currículo, não aludimos apenas ao currículo prescrito “organizado em disciplinas apresentadas em regimentos, planos, programas de ensino, projetos, materiais didáticos, portais e outros documentos" (ALMEIDA; VALENTE, 2011, p. 15), mas a um currículo vivo, construído na prática pedagógica, ressignificado, (re)construído na ação, em sala de aula, durante interações entre professor e alunos. Um "currículo aberto à criatividade e ao desconhecido, que acolhe o inesperado e possibilita novas emergências... indo além do planejado, do esperado [...] um currículo em ação, em movimento, que dialoga com o cotidiano e com o indeterminado...” (MORAES, 2010, p. 15). Assim, o currículo é construído na ação, em que "estão envolvidos tanto os conhecimentos científicos como os elementos simbólicos culturais, os saberes da prática docente, as práticas sociais de comunicação, as técnicas e os artefatos" (ALMEIDA; VALENTE, 2011, p. 29).

Sobre o processo de integrar tecnologias digitais ao currículo na escola em que foi realizada a pesquisa, trazemos mais alguns trechos de relatos de professoras. Foi necessário fazer escolhas de alguns momentos, falas, tecnologias, pois foram dois anos interagindo com as professoras, vivenciando a escola, e muito se produziu... Iniciamos com o relato da 
professora Léa, que atuava na escola com alunos do 1. ${ }^{\circ}$ ano do Ensino Fundamental:

A internet funcionou. Pegava duas barrinhas [se referindo a marcação do nivel de conexão], às vezes dava uma travada, mas melhor do que nada. Internet disponível é outra vida. Eu estava explicando das contribuições dos índios. Estava falando da mandioca, falei do pé da mandioca. Um aluno perguntou:-Professora, como é o pé de mandioca? Eu falei: - Não tem o pé de manga, a mangueira? Assim também tem o pé de mandioca. Nunca viu um pé de mandioca? Não. Nunca tinham visto a planta. Eles não sabiam que era uma raiz. Eu fui lá pesquisar, e fui mostrando imagens da planta, da raiz. Isso é bom, porque usamos a internet quando vai surgindo a dúvida. Como eu vou desenhar um pé de mandioca? Vou pintar? Se não tem esse recurso, não fica real. Então fui pesquisando, eles (os alunos) foram perguntando outras coisas, a aula flui, você vê assim, que se tivesse internet em todas as salas... as aulas seriam diferentes (Profa. Léa, 11.12.2017).

Esse relato se refere à integração da internet em sala de aula, em uma ação pedagógica, com alunos do $1 .^{\circ}$ ano. Mais do que isso, revela a maneira de como a professora modificou sua aula a partir do uso da internet, por ela estar acessível na sala. Afinal, há diferença em ver imagens, fotos, de uma raiz de mandioca, e desenhá-la no quadro, como comentou a professora! Quantas informações puderam ser exploradas com o acesso à internet? Quanta inovação teve nessa aula em relação a uma aula sem internet? Tratava-se de informações integradas ao currículo em ação, ao conteúdo em estudo, a partir de uma dúvida de alunos, explorada a partir de imagens e vídeos, de informações que seriam diferentes se fossem apresentadas somente no quadro e giz.

Os conhecimentos da professora sobre a possibilidade de pesquisar essas dúvidas na internet, no momento da dúvida, e a disponibilidade do notebook e projetor multimídia modificaram os processos de ensino e de aprendizagem naquela aula, além da abertura em alterar o planejamento da aula, na aula, considerando conhecimentos que emergiram no currículo em ação. Esse movimento também está de acordo com o que Mishra e Koehler (2006, p. 1018) argumentavam: "apenas inserir a tecnologia no processo educacional não é suficiente. A questão do que os professores precisam saber para que consigam incorporar a tecnologia apropriadamente em seu ensino precisa ser pesquisada". Portanto, os modos como as professoras usam essas tecnologias, seus conhecimentos podem modificar os processos de ensino e os processos de aprendizagem de seus alunos; podem potencializar o processo de integração das tecnologias disponíveis nas escolas.

Também sobre o processo de integração de tecnologias, no caso do projetor e notebook, 
resgatamos uma fala da professora Ana:

Esses dias, na aula de Português, eu coloquei um vídeo para contar a história do ursinho feio, que vai contar também a história dos sólidos geométricos. Eu já trabalhei o que é aresta, o que é vértice, ... eu acho que essa tecnologia vem auxiliar muito nessa parte, principalmente quando está disponível. $O$ Datashow ficou à disposição, e como eu tinha terminado a outra atividade, eu já coloquei aquele vídeo, e eu achei que com as tecnologias, eles (os alunos) perguntam, fica bem mais interessante. Está ficando algo comum, porque antes, quando eu colocava (o projetor) era aquela brincadeira com as mãos lá na frente, aquela coisa toda diminuiu, eles não estão mais fazendo tanto, está ficando uma coisa normal. Está ali comum, fazendo parte da metodologia, e isso muda bastante. É uma coisa que daí não se perde mais tanto tempo, com o encantamento, eles já sabem que é para aprender (Profa. Ana, 09.10.2017).

Nesse relato podemos considerar que a professora Ana, que atuou em 2017 com uma turma de alunos do $3 .^{\circ}$ ano do Ensino Fundamental, ainda sentia falta de melhores condições estruturais na escola, ainda cobrava por mais acesso à internet, mas nem por isso deixava de utilizar as tecnologias digitais disponíveis em suas aulas. Na aula relatada, ela fez uso do projetor integrado ao notebook para explorar conteúdo da Língua Portuguesa, mas, a partir dos assuntos divulgados no vídeo, conseguiu explorar tópicos da Matemática também. Logo, a partir da aula com vídeo, dos conhecimentos sobre os conceitos nele explorados, a professora conseguiu modificar sua aula, pesquisar temas que seriam diferentes, se a professora fizesse apenas a leitura do livro, ou optasse por outras formas de apresentá-los.

A professora Ana observou que as aulas se modificaram/transformaram, que os alunos não brincavam mais tanto de sombras (não que isso também não fosse interessante) quando se fazia uso do projetor multimídia em outras aulas. Vale lembrar que, quando iniciamos as ações de formação nessa escola, uma das queixas mais frequentes das professoras era a de que os alunos confundiam aula de informática com lazer, com jogos. E, pelo observado, a partir dos planejamentos, das conversas, das diferentes ações desenvolvidas pelas professoras em sala de aula, na sala de tecnologias, a visão dos alunos sobre essa prática com tecnologias passou a ser natural na escola, no sentido de que as tecnologias estavam naturalizadas naquele ambiente, estavam invisíveis/sendo integradas.

Os alunos passaram a compreender que se pode estudar em ambientes diferentes (sala de aula, sala de tecnologias, biblioteca); que as variadas atividades propostas, independentemente dos recursos adotados, visam o aprender, a construção de conhecimento; 
que os alunos podem questionar, dialogar e contribuir com ideias complementando o que se observa; e é claro que a professora aproveitava essas oportunidades para explorar outros conteúdos, outras atividades, outras disciplinas... agindo, interagindo, questionando, avaliando...

Sobre dificuldades que as professoras perceberam no início das ações de formação e que foram vencidas aos poucos, a professora Bia comentou:

Eu acho que uma coisa bem bacana no projeto é que, logo que eu entrei na sala, falava que íamos para a sala de tecnologias, todo mundo ficava feliz, isso continua, eles continuam ficando felizes no dia da sala de informática. A questão é que quando chegavam lá e era atividade, não queriam fazer, queriam ir para sala de informática e sempre jogar. [...] Depois de determinado tempo, as crianças começaram a entender que podiam ir para sala de informática e fazer atividade diferenciadas, e que isso não era chato, era uma forma de aprendizagem também, e elas começaram a aceitar mais e não ficava aquela reclamação o tempo todo, de que a gente vai para sala de informática e não pode jogar (Profa. Bia 12.12.2017).

Esse relato vem corroborar que, a partir de algumas ações realizadas nesse estar juntos (pesquisadoras, professoras e alunos), as professoras conseguiram observar mudanças/transformações em suas aulas, mas também nos comportamentos de alunos em face das aulas com tecnologias. Podemos dizer que nas ações de formação (reuniões de planejamento, observações de aulas e reuniões coletivas de avaliação) ocorreram vários momentos de conversas, interações, diálogos para construir conhecimentos, para possibilitar/potencializar esse movimento para integrar tecnologias digitais ao currículo. Observamos que as professoras tiveram iniciativa, agiram, conversaram com seus alunos e conseguiram obter resultados/movimentos de transformação com relação a esses hábitos trazidos pelos alunos de anos anteriores.

Nessa turma de $3 .^{\circ}$ ano, gerenciada pela professora Bia, as aulas passaram de momentos mais de lazer para momentos de aprendizagem... e não foi ruim para os alunos, que continuaram felizes ao habitarem esse espaço. Isso nos motiva a pensar na importância do estar junto, nesse processo de formação, que possibilitou a construção de conhecimento, que na ação, nas práticas pedagógicas, as professoras puderam integrar tecnologias e transformar suas aulas, além de favorecer a aprendizagem de seus alunos.

Quanto ao processo de integração de tecnologias digitais em aulas, principalmente nessa interação com nativos digitais, a professora Bia comentou: 
Com relação a essa integração de tecnologias..., as crianças são bem integradas. Certa vez uma menina perguntou uma coisa que no momento eu não sabia responder, eu falei que ia pesquisar, ela imediatamente falou: Professora, liga seu celular e pesquisa agora para termos essa resposta. Ela me deu o start, posso fazer isso agora, eu estou com internet aqui no celular, eи pesquisei e falei o que era. Isso que eu sou uma pessoa que não sou tão desconectada, mas elas são muito mais .... Isso foi bem legal, e foi ali que eu comecei a usar o celular para fazer algumas pesquisas em sala de aula, para responder alguma coisa instantaneamente (Profa. Bia 12.12.2017).

Esse relato nos faz pensar na potencialidade do celular em sala de aula, na importância da conexão com a internet, na possibilidade de integrar essas tecnologias de acordo com o interesse dos alunos (que são nativos digitais), conforme a demanda das aulas. No caso dessa aula, a professora Bia estava integrando o celular à sua prática pedagógica, mas não era um uso forçado, e, sim, consciente, a partir de uma busca na internet e da necessidade do momento; para promover a aprendizagem de determinado conceito/conteúdo, que nasceu do interesse de um dos alunos; emprego de um recurso (o celular conectado à internet) de que a professora dispunha, tinha conhecimentos para utilizar (pois relatou ser uma pessoa conectada), mas que a partir daquele momento passou a ser/estar integrado a suas práticas pedagógicas.

Por fim, apresentamos ainda um relato da professora Léa sobre como ela usava o vídeo em aula:

Para explicar algum conteúdo, eu sempre uso o vídeo para dar uma introdução. Quando eu vou explicando no quadro, é mais complicado, porque eu tenho que desenhar, tenho que fazer todo um contexto. Agora no vídeo é muito mais pontual. Por exemplo, a multiplicação, eu tentei começar a aula explicando, mas eu vi que estava confundindo a cabeça deles. Eu tinha preparado o vídeo para depois, para uma outra atividade, mas eu passei o vídeo antes, e achei que foi mais fácil deles (os alunos) entenderem. [...] Com $o$ vídeo tem todo o contexto, tem som, foi mais fácil para eles entenderem. Eles sempre lembram, já entenderam que no vídeo tem informação. Quando eu passo vídeo, não é o vídeo por vídeo, sentar e assistir um desenho, isso eles já não têm mais, [...] eles sabem que tem um objetivo, que a partir dali (do vídeo) vamos continuar nossa aula [....] $O$ vídeo tem som, tem imagem, tem todo um contexto, que inicia com uma ideia, fecha uma ideia, e eu consigo alcançar muito mais do que apenas explicando. Eu gosto desse recurso, não por desenho, mas por explicação de conceito, explicação de conteúdo, porque é difícil chegar a fundo pra criança (Profa. Léa, 11.12.2017).

Os conhecimentos da professora, em suas aulas com o uso do vídeo, modificaram/transformaram o processo de ensino e de aprendizagem dos alunos, uma vez que envolveram outros contextos, outras linguagens (digital, som, imagem), e favoreceram a 
compreensão de conceitos pelos alunos, oportunizaram o repensar da prática pedagógica, uma vez que deu indícios de que essa tecnologia estava sendo integrada às aulas. Aos olhos dos alunos, essa tecnologia parecia invisível, no sentido de eles se envolverem nas atividades propostas, sem que ela chamasse a atenção, apenas o que se produzia de conhecimentos a partir dela.

Por meio do depoimento dessa professora pudemos pensar no processo de construção de conhecimento CTPC, estudado por Mishra e Koehler (2006), que o definiram como um conhecimento amplo que envolve a inter-relação entre os três conhecimentos (pedagógico, tecnológico e de conteúdo); o conhecimento do uso de tecnologias para ensinar e aprender um conteúdo específico, ou seja, o conhecimento do professor sobre o conteúdo que deseja ensinar e como ensiná-lo (processos, estratégias de ensino) utilizando-se de tecnologias. Nesse caso, a professora relatou sentir a necessidade de adotar essa tecnologia (o vídeo) para contextualizar, explicar e facilitar a compreensão de determinados conceitos (a multiplicação, por exemplo) explorados em sala de aula com os alunos.

Referimo-nos a processo de construção, pois Becker (2012, p. 35) afirmou que "a ação do sujeito constrói conhecimento", e, nesse caso, a professora estava agindo, ao planejar, (re)planejar, transformar sua aula, com o uso de vídeos. Além disso, ela estava construindo conhecimento a partir das ações que ela praticava, ao interagir com seus alunos, com as tecnologias, com o contexto, pois "o conhecimento resulta de interações entre sujeito e objeto" (BECKER, 2012, p. 37). Não eram ações pontuais, mas envolviam conhecimentos sobre o currículo, os conteúdos propostos, as metodologias, os modos de relacionar aquela aula com outras, em momentos outros, com conhecimentos outros...

Enfim, a partir desses poucos relatos, podemos considerar que houve construção de conhecimentos CTPC dessas professoras, durante o processo de formação continuada com/para integrar tecnologias ao currículo, porquanto, pelos relatos, as práticas não eram mais de inserir tecnologias em aulas, e, sim, movimentos de agir, interagir, construir, inventar, refletir, (re)pensar, de integrar. Certamente, são conhecimentos que as professoras construíram, reconstruíram, e (re)construirão em outras situações, outros momentos de aula, pois "a ideia central desses processos é a de que o sujeito constitui-se na medida do que ele faz. Ele extrai do que ele fez hoje, o que ele será amanhã” (BECKER, 2012, p. 57).

Eis um pouco sobre o início de um processo de integração, até porque há muitas tecnologias ainda a serem exploradas, mas podemos pensar que algumas ações dessa formação 
(como as reuniões de planejamento, as observações de aulas, as reuniões coletivas de planejamento) podem ter mobilizado esse início... No entanto, não foi somente o processo de formação que mobilizou essas ações, mas também a atitude de abertura das professoras, dos alunos, da escola, entre tantas outras ações e emoções que não couberam nesta narrativa... E, por falar em emoções, voltemos à composição de Sater e Oliveira (1990) para se referir a esse processo de integração de tecnologias digitais ao currículo escolar, lembrando que: "É preciso amor pra poder pulsar. É preciso paz pra poder sorrir. É preciso a chuva para florir...”.

\section{ALGUMAS CONSIDERAÇÕES}

Neste artigo, apresentamos uma narrativa sobre alguns movimentos de um processo de formação continuada vivenciado por professoras dos anos iniciais, em uma escola pública de Campo Grande/MS. Esta narrativa conta uma experiência desse processo em uma escola, apresentando alguns trechos de relatos dessas professoras; narramos sobre alguns aspectos dessa formação, mas há outros elementos, outros olhares, outros relatos... outras narrativas que podem ser produzidas.

Podemos considerar que esse estar juntos (pesquisadoras e professoras) oportunizou momentos de formação/aprendizagem, tanto para nós, pesquisadoras, que pudemos vivenciar a rotina do ambiente escolar, como para as professoras, que puderam ter momentos de construção de conhecimento, de ação, interação, diálogo e vivências de outras rotinas na escola. Portanto, a partir da narrativa apresentada neste artigo, podemos identificar que as reuniões de planejamento, a observação/participação/acompanhamento em aulas desenvolvidas e as reuniões coletivas de estudo e avaliação podem ter sido ações dessa formação continuada, em serviço, que proporcionaram às professoras reflexões sobre mudanças de suas práticas: sempre agindo, pensando, problematizando. Mais do que isso, desenvolver aulas com o uso de tecnologias digitais que possam favorecer a aprendizagem de seus alunos e um movimento de construção de CTPC para integrar tecnologias digitais ao currículo.

Enfim, tivemos oportunidade de vivenciar/acompanhar esse processo, no cotidiano das professoras, no contexto em que elas atuam, no espaço/tempo em que o currículo é construído, quando surgem as dificuldades, e conversar sobre as possibilidades de integrar tecnologias digitais disponíveis para favorecer aprendizagens. Esse caminhar revelou que ainda há muitos desafios nesse movimento de integrar tecnologias digitais ao currículo, entre eles podemos 
citar: a infraestrutura da escola, que nem sempre estava de acordo com o desejado; o tempo das professoras, que vivem suas rotinas diárias e nem sempre conseguem se dedicar o quanto desejam para estudos, pesquisas e interações; o investimento em políticas de formação, como essa proposta, que permitiram construir com as professoras propostas de ação para a sala de aula, escola... inclusive para realizar mais estudos sobre aplicativos, softwares e jogos que possam ser integrados ao currículo dos anos iniciais do Ensino Fundamental.

Esta foi apenas uma narrativa... de um processo de formação... em uma escola... com um grupo de professoras e pesquisadoras... Todavia, são tantas narrativas... tantos processos de formação... tantas escolas... com tantos grupos de professores... e tantos grupos de pesquisadores... e muito por investigar e fazer nas escolas para integrar tecnologias digitais ao currículo.

\title{
AGRADECIMENTOS
}

À FUNDECT/CAPES por financiar esta pesquisa e à Coordenação de Aperfeiçoamento de Pessoal de Nível Superior - Brasil (CAPES) - Código de Financiamento 001.

\section{REFERÊNCIAS}

\begin{abstract}
ALMEIDA, Maria Elizabeth Biancocini de; VALENTE, José Armando. Tecnologias e currículo: trajetórias convergentes ou divergentes? São Paulo: Paulus, 2011.
\end{abstract}

BECKER, Fernando. Educação e construção de conhecimento. 2. ed. Porto Alegre: Penso, 2012.

BITTAR, Marilena. A abordagem instrumental para o estudo da integração da tecnologia na prática pedagógica do professor de matemática. Educar em Revista, Curitiba, número especial 01, p. 157-171, 2011. Disponível em: http://www.scielo.br/pdf/er/nse1/11.pdf. Acesso em: 10 mar. 2020.

CORRÊA, Bárbara Drielle Roncoletta. Entre narrativas, gaiolas e voos: movimentos de integração de tecnologias digitais de uma professora dos anos iniciais. Orientadora: Suely Scherer. 2019. 188 f. Dissertação (Mestrado em Educação Matemática) - Universidade Federal de Mato Grosso do Sul, Campo Grande, 2019.

FREIRE, Paulo. Pedagogia da autonomia: saberes necessários à prática educativa. 25. ed. São Paulo: Paz e Terra, 1996.

LOBO DA COSTA, Nielce Meneguelo. Reflexões sobre tecnologia e mediação pedagógica na formação do professor de matemática. In: BELINE, Willian; LOBO DA COSTA, Nielce 
Meneguelo (Orgs.). Educação matemática, tecnologia e formação de professores: algumas reflexões. Campo Mourão: Editora da FECILCAM, 2010. p. 85-116.

MISHRA, Punya; KOEHLER, Matthew J. Technological pedagogical content knowledge: a framework for teacher knowledge. Teachers College Record, v. 108, n. 6, p. 1017-1054, Jun. 2006.

MORAES, Maria Cândida. Complexidade e currículo: por uma nova relação. Polis [on-line], v. 25, 2010. Disponível em: http://journals.openedition.org/ polis/573. Acesso em: 15 maio 2019.

PAPERT, Seymor. A máquina das crianças: repensando a escola na era da informática. Tradução Sandra Costa. Porto Alegre: Artmed, 2008.

RODRIGUES, Alessandra.; ALMEIDA, Maria Elizabeth Biancocini; VALENTE, José Armando. Currículo, narrativas digitais e formação de professores: experiências da pósgraduação à escola. Revista Portuguesa de Educação [on-line], v. 30, p. 61-83, jan./jun. 2017. Disponível em: https://www.redalyc.org/pdf/374/37451307004.pdf. Acesso em: 23 fev. 2020.

SÁNCHEZ, Jaime. Integración curricular de TICs. Concepto y modelos. Enfoques Educacionales, v. 5, n. 1, p. 51-65, jan. 2003. Disponível em: https://www.researchgate.net/publication/261947915_Integracion_Curricular_de_TICs_Conc epto_y_Modelos. Acesso em: 12 fev. 2020.

SATER, Almir Eduardo Melke; OLIVEIRA, Renato Teixeira de. Tocando em frente (letra de música). 1990. Disponível em: https://www.youtube.com/watch?v=SWtjTkixv5M. Acesso em: 10 mar. 2020.

SCHERER, Suely. Integração de laptops educacionais às aulas de matemática: perspectivas em uma abordagem construcionista. In: ROSA, Maurício; BAIRRAL, Marcelo Almeida; AMARAL, Rúbia Barcelos (Orgs.). Educação matemática, tecnologias digitais e educação a distância: pesquisas contemporâneas. São Paulo: Editora Livraria da Física, 2015. p. 163186.

VALENTE, José Armando. Formação de professores: diferentes abordagens pedagógicas. In: VALENTE, José Armando (Org.). O computador na sociedade do conhecimento. Campinas/SP: Unicamp/Nied, 1999. p. 99-115.

Recebido em: 30/03/2020

Aprovado em: 05/06/2020 